\title{
PALMAS: POR UM SISTEMA DE ESPAÇOS LIVRES
}

\author{
PALMAS: FOR AN OPEN SPACES SYSTEM
}

\section{Glauco de Paula Cocozza}

Professor doutor, adjunto do curso de Arquitetura e Urbanismo UFT

e-mail: gcocozza@uft.edu.br

\section{Lucimara Albieri de Oliveira}

Professora Msc. assistente do curso de Arquietura e Urbanismo UFT

e-mail: lucimara.arq@grupobonafide.com.br

\section{Artur Alvarenga Santiago}

Graduando do curso de Arquitetura e Urbanismo UFT; bolsista PIBIC e-mail: artursantiago@hotmail.com

\section{Diego de Araújo Sousa}

Graduando do curso de Arquitetura e Urbanismo UFT; PIVIC

e-mail:digbassop@bol.com.br

\section{Joanice Silva Coelho}

Graduanda do curso de Arquitetura e Urbanismo UFT; bolsista PIBIC e-mail: joanicinhacoelho@hotmail.com

\section{RESUMO}

A recente história da cidade de Palmas revela um conjunto de condicionantes projetuais, políticos, sociais, e, principalmente, culturais que moldaram a forma urbana planejada da cidade, imprimindo, no espaço, marcas dos conflitos que determinaram sua urbanização. Esses são impressos em sua arquitetura, em seu processo de ocupação territorial, na destruição de parte da paisagem natural e, principalmente, nos generosos espaços livres que o plano como um todo idealizou e que caracterizam o objeto de estudo deste trabalho.

Palavras-chaves: Palmas, espaço livre, espaço público, forma urbana, paisagem.

\begin{abstract}
The recent history of Palmas city reveals a conjunct of designs, political, socials, and mainly cultural characteristics that shaping the planned urban form, printing in the space conflicts marks that determinate your urbanization. This are printed in your architecture, in the territorial occupation process, in the destruction in part of natural landscape and mainly in the generous open spaces that the plan idealized and that characteristics the study object of this work.
\end{abstract}

Key words: Palmas, open space, public space, urban form, landscape.

\section{DO CONCEITO AO CONTEXTO}

A última cidade brasileira planejada do século XX depara-se, na atualidade, com questões e conflitos os quais, mesmo o projeto urbanístico não conseguiu evitar. Situada 
no "coração" do Brasil, onde seu desenvolvimento traduz uma imagem de progresso em meio ao cerrado brasileiro, ela se insere em uma paisagem singular, dominando o imaginário dos moradores da região com sua modernidade, em um ecossistema identificado, na atualidade, por seu potencial ambiental e econômico.

Parte desse valor ocorre pelo grande potencial agrário, logístico e hidrelétrico da região, onde o relevo adequado a diferentes atividades e a abundância de água gera investimentos maciços de empresas privadas e uma estratégia governamental de ocupação do território brasileiro para o interior do país. Essa teve origem no ciclo do ouro, seguida pela expansão agrária, intensificada na metade do século XX pela criação de Braślia, acarretando um surto populacional e urbanístico decisivo para o desenvolvimento da região, resultando no crescimento de inúmeras cidades e na criação de outras, planejadas ou espontâneas.

Palmas se insere na continuidade desse contexto. A mais nova capital de um estado brasileiro, o Tocantins, criado na Constituição de 1988, dividiu a área do estado de Goiás ao meio, deixando o norte, região menos desenvolvida, para a criação de um estado que pudesse representar a melhoria da qualidade de vida de uma população marcada por inúmeros conflitos sociais e pela ausência de ações governamentais e iniciativas privadas capazes de mudar o panorama de esquecimento em relação ao restante do país (Figura 1). A criação do estado e da nova capital trouxe não só para a população local, mas como para milhares de brasileiros, a esperança de conquista na qual, assim como Brasília, o cerrado é novamente palco e agente do desenvolvimento, gerando uma modificação irreversível quanto à transformação e ocupação dessa paisagem.

O cerrado brasileiro é a segunda maior formação vegetal brasileira, e uma das paisagens menos valorizadas no que tange à sua preservação (Figura 2). Sua paisagem

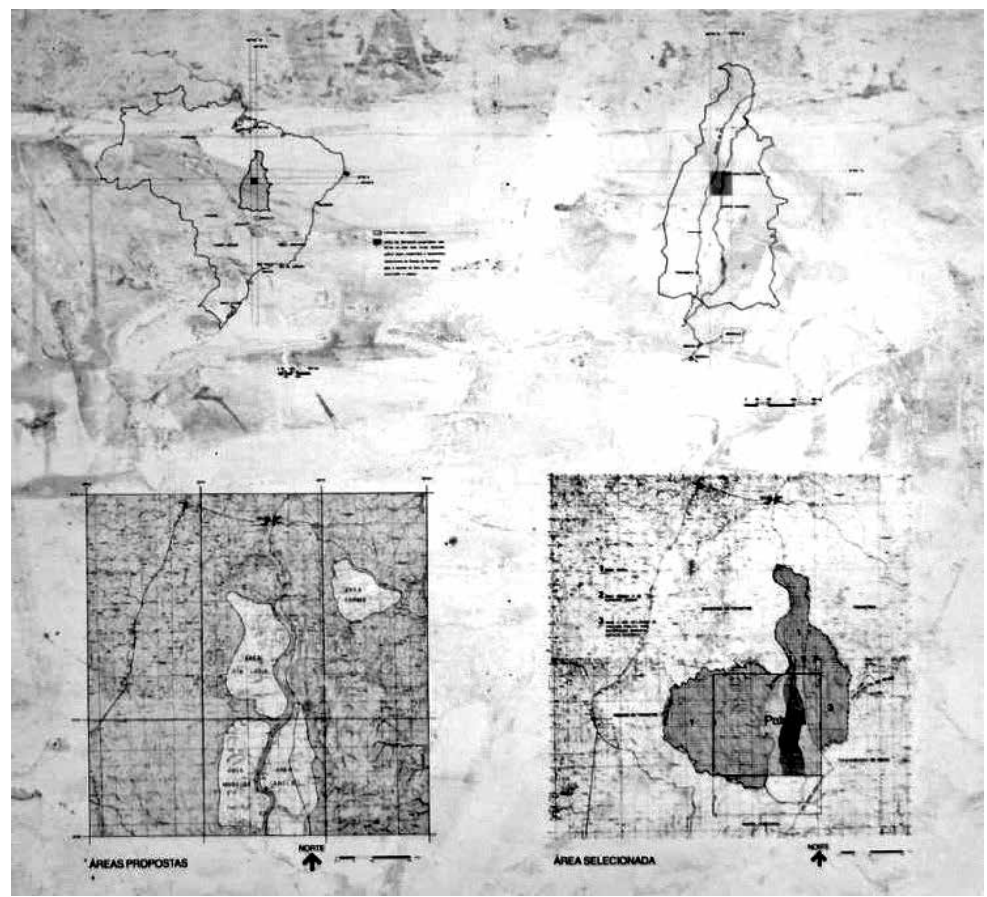

Figura 1:

Mapa da localização do estado do Tocantins e da cidade de Palmas. No canto inferior esquerdo, as quatro áreas possíveis para a implantação da capital e, ao lado, a área escolhida Fonte: SEMUC, 2006 
é, para muitos, agressiva, e por isso, durante muito tempo, foi considerada uma área perdida para a economia do país. É comum ver manifestações apaixonadas em defesa do cerrado, assim como é feito pela Mata Atlântica, Pantanal, Floresta Amazônica e até da Caatinga. O que se vê, porém, são focos desconexos de discussão do real valor desse ecossistema para o equilíbrio ambiental e econômico brasileiro, sob o ponto de vista de gestores, pesquisadores e, principalmente, de seus moradores.

A presença de três das maiores bacias hidrográficas da América do Sul (TocantinsAraguaia, São Francisco e Prata), onde predomina o ecossistema do cerrado, favorece sua biodiversidade. A cidade de Palmas localiza-se no centro do estado, na bacia do rio Tocantins, a qual faz parte de um plano de conservação do cerrado. Este apresenta uma diversidade de paisagens divididas em interflúvio, caracterizadas pelo cerrado strictu sensu, cerradão, campo rupestre e campo sujo, e pelas paisagens associadas a cursos d'água, como as matas de galeria, os buritizais, as veredas e os campos úmidos. A paisagem de Palmas engloba o cerrado strictu sensu, matas de galeria nos fundos de vale dos córregos que cortam a cidade, além de buritizais nos limites do plano, caracterizando uma diversidade de contextos nos quais a cidade foi inserida.

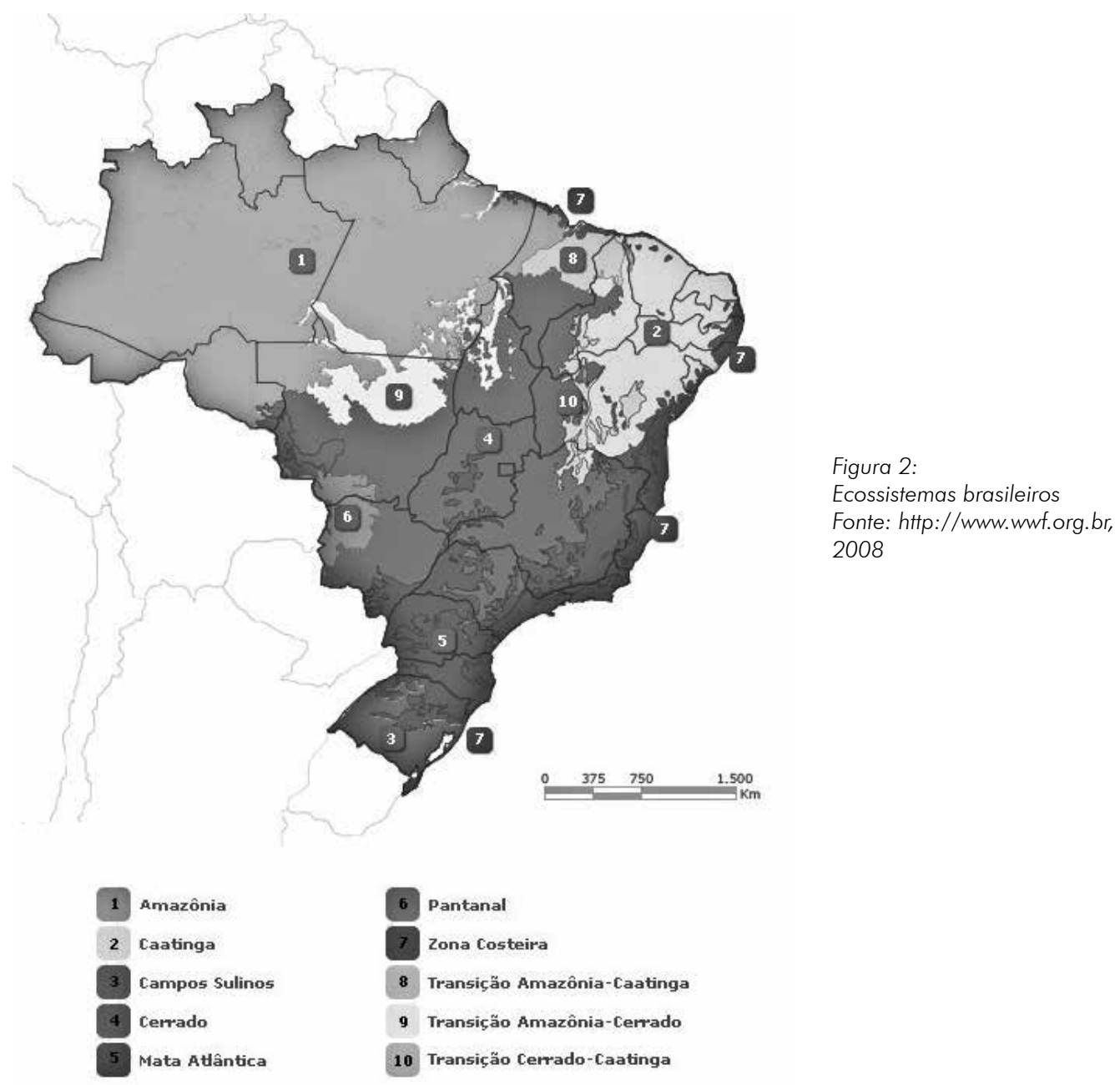




\section{ESPAÇO E PAISAGEM EM PALMAS}

Abordar o tema paisagem na cidade de Palmas é ir a seu ponto de partida, ao conceito do projeto como um todo, seus esboços iniciais e organização espacial, onde a urbe não é simplemente inserida na paisagem natural, mas integrada ao seu ecossistema. A cidade é resultado da apreensão do fragmento da paisagem do cerrado brasileiro.

A sua paisagem é marcante, desconhecida por muitos e tocante na visão de quem a conhece. Ao mesmo tempo em que a cidade repousa entre a serra e o lago, e seu traçado viário rasga a mata, ela renega, culturalmente, sua história e elimina alguns traços de sua memória. Construir paisagens significa sobrepor estruturas, condicionando o espaço às novas necessidades do homem.

Se, para Milton Santos (1991), a paisagem é o resultado de acumulação de tempos, a de Palmas pode se caracterizar pelas distintas etapas, antes de sua construção: natural; do projeto: ideal; e de sua conformação: real. A forma da cidade fez com que esta acumulasse outros elementos para definir sua memória, principalmente os símbolos de sua construção: avenidas, palácios e praças, todos definidos pelo traçado, que se perpetuam como herança de um momento histórico o qual modificou a paisagem e transformou-se em ícone do progresso regional.

Os danos da acumulação antrópica e da transformação da natureza primeira em segunda foram inevitáveis. Os impactos causados pela consolidação de sua área urbana são conflitantes quando analisados pelo discurso e pela prática, pois onde a transformação do cerrado foi mais intensa, os espaços se configuraram distantes dos valores culturais existentes no ecossistema. Esses, impostos pela ação antrópica, adquiriram novos valores e imaginários construídos com a inserção de elementos de diferentes culturas que povoaram a cidade e formaram a identidade urbana. As avenidas rasgadas na paisagem são, hoje, os novos valores construídos com a transformação da paisagem, concedendo a noção exata, não do projeto urbano em sua totalidade, mas de sua relevância quanto espaço da representação de uma nova sociedade.

O projeto, segundo o Grupo Quatro', priorizou a consolidação de quatro diferentes categorias de espaços livres em meio ao desenho urbano e à paisagem natural. A primeira e mais emblemática é a do espaço iconográfico (Figura 3). Os edifícios das instâncias estadual e municipal, foram locados em áreas onde os pedestres pudessem transitar e permear as edificações, junto de grandes espaços livres, participando e convivendo, de perto, do cotidiano desses elementos. Nasciam, desse modo, os espaços monumentais da cidade, marcos urbanos, seguindo os princípios de percepção urbana de Lynch.

A segunda categoria se encontra nas quadras residenciais e comerciais, respeitando a Lei n. 6.766, que destina 35\% da área de cada uma para espaço livre. Cada quadra foi estipulada para ter um desenho próprio. A diferenciação dos traçados de cada uma define, segundo seus autores, seu caráter e identidade contemporâneos.

"Prevalecem para o Micro Parcelamento, como facultado pelo art. 4, inciso I e parágrafo 1 da lei 6766 de dezembro de 1979, um mínimo de 15\% para as Áreas Públicas Municipais e um mínimo de 35\% para a soma destas com o sistema 


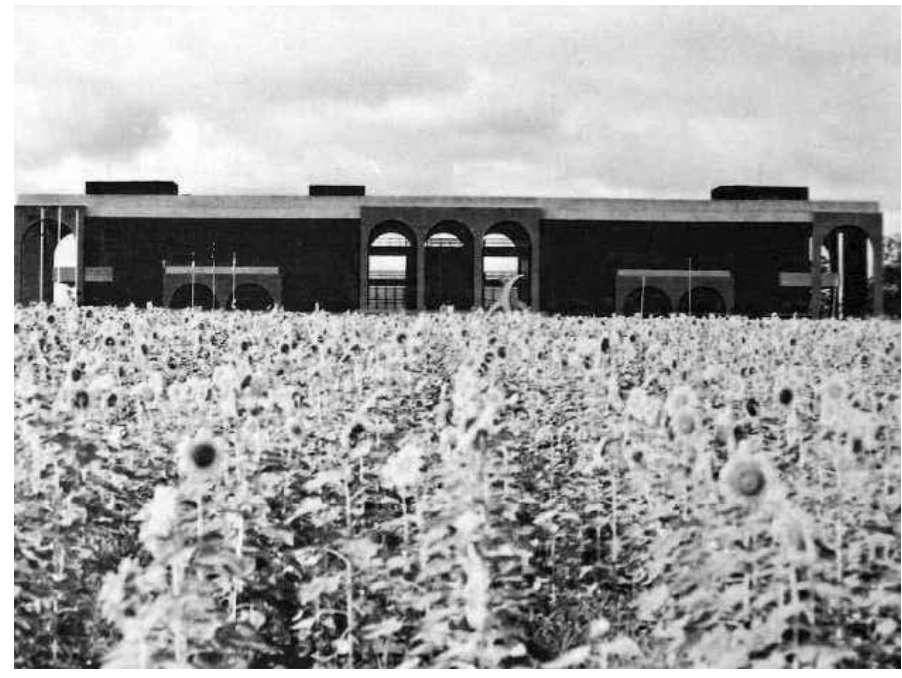

Figura 3:

Praça dos Girassóis: marco iconográfico da cidade Fonte: SEMUC, 2005

viário, computados sempre tendo como perímetro aquele definido pelos eixos das vias do sistema viário principal definido das glebas urbanas objeto de loteamento." (Lei municipal n. 468: capítulo III, art. 7o, n. II, 1994).

"A cidade, portanto, deverá desenvolver no seu todo, em uma escala gregária mais aconchegante, ficando os amplos planos verdes somente reservados aos espaços que caracterizam como 'civitas'. Quanto à escala 'urbe', será garantida pelas inúmeras ruas centrais de pedestres que deverão resgatar aspectos positivos das cidades antigas. Essas passagens deverão se abrir para praças com chafarizes e árvores, podendo ser localizados no casario adjacente o comércio fino de varejo, como pequenas lojas, cafés, pousadas e edifícios para escritórios, etc." (GRUPO QUATRO, 1989)

A terceira categoria se refere às áreas de preservação e proteção (Figura 4). Trata-se de um sistema de espaços livres na cidade em meio à formação urbana já consolidada, delimitando o contexto natural e o antrópico. Os rios que correm da serra para o lago, alimentando o rio Tocantins, não são apenas as bordas naturais e limites para o crescimento da cidade, mas estruturam um sistema de espaços livres, fundamental para sua qualidade ambiental.

"Propõe-se um sistema de áreas verdes composto pelo parque Ecológico, Parques Urbanos, Parques Lineares, pelas áreas Verdes Comunitárias, que alcançarão um índice de $19 \mathrm{~m}^{2} /$ habitante, superando portanto os índices internacionais estabelecidos pela Unesco." (GRUPO QUATRO, 1989)

A quarta categoria é a dos espaços livres utilitários. Estes apresentam função estrutural na cidade, seja pela manutenção do zoneamento proposto, seja pela reserva de áreas para o transporte ou por outros elementos de seu desenvolvimento. Esse é o caso da avenida Teotônio Segurado, eixo estrutural da cidade, que contém uma "ilha" 
de área verde destinada, inicialmente, ao transporte de massa, mas que se tornou, durante a construção de Palmas, um ícone do progresso ao rasgar o cerrado existente e renegar a paisagem natural como elemento de composição de seu espaço (Figura 5).

Apesar do traçado viário e do desenho do parcelamento terem sido mantidos, a forma de ocupação da cidade não ocorreu da maneira planejada. Mas em qual parte desse processo o desenvolvimento da cidade rompe com o plano, descaracterizando sua concepção inicial e sacramentando os problemas que a cidade enfrenta na atualidade? A ação do governo, o qual se encarregou de ser o principal loteador e gestor
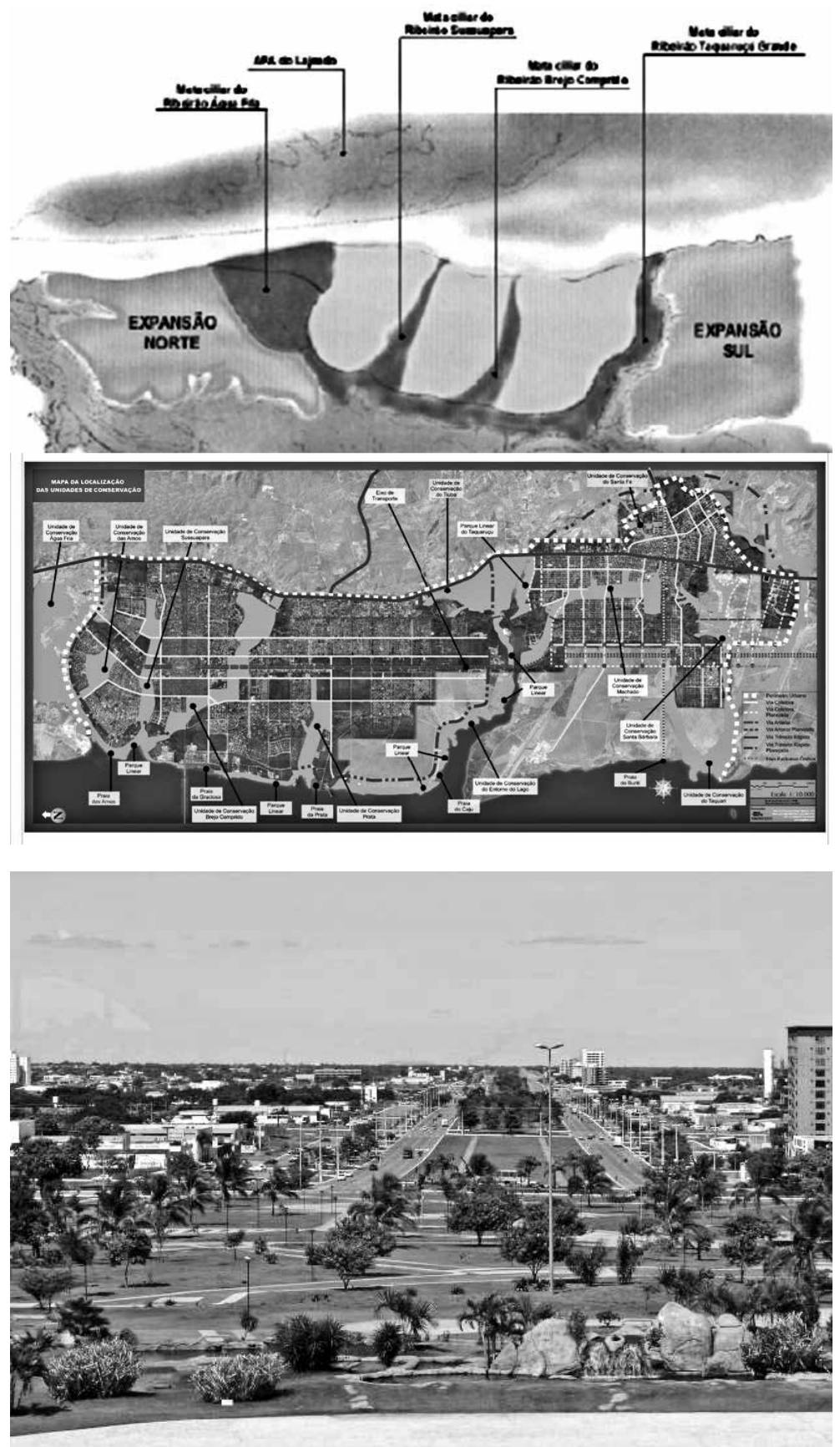

Figura 4:

Áreas de preservação e proteção de Palmas segundo o plano e as áreas de conservação propostas pelo plano diretor de 2007

Fonte: IPUP, 2007
Figura 5:

Espaço livre utilitário da cidade: Avenida Teotônio Segurado

Fonte: Autores, 2005 
do plano, proporcionou uma situação de desenvolvimento na cidade que mesmo os mais hábeis planejadores urbanos não poderiam evitar - a cidade era um ideário político e não urbano. Independente do plano, provavelmente essas ações ocorreriam de qualquer maneira.

Analisando os desenhos da apresentação do projeto da cidade, pode-se observar como era previsto seu desenvolvimento ordenado e programado. $O$ plano projetava o crescimento em faixas no sentido leste-oeste a partir de seu centro cívico, sempre delimitadas pelos limites do antrópico e da natureza, principalmente os fundos de vale (Figura 6). De acordo com o plano da nova capital, a cidade deveria ocupar todo seu território no ano de 2010. Em 2008, a cidade, morfologicamente, distancia-se dessa estratégia e redesenha seu espaço, utilizando as áreas destinadas a futuras expansões para locar grande parte da população, principalmente os trabalhadores que chegaram no início da construção e não tinham condições de estabelecerem-se na área central.

Os primeiros gestores da cidade e do estado foram os grandes incentivadores das ocupações em desacordo com o plano, concretizadas em bairros afastados da região central e que, atualmente, concentram metade da população do município. Cada gestão aplicou e interpretou o plano, desfigurando a idéia inicial, deixando sua marca na forma de ocupar o território ainda desabitado (Figura 7). Essas feridas são reveladas, atualmente, pelo esforço dos atuais gestores, na tentativa de minimizar e solucionar os problemas causados por sua apropriação indevida.

O crescimento da cidade desvirtuou-se do projeto original, agregando, em seu

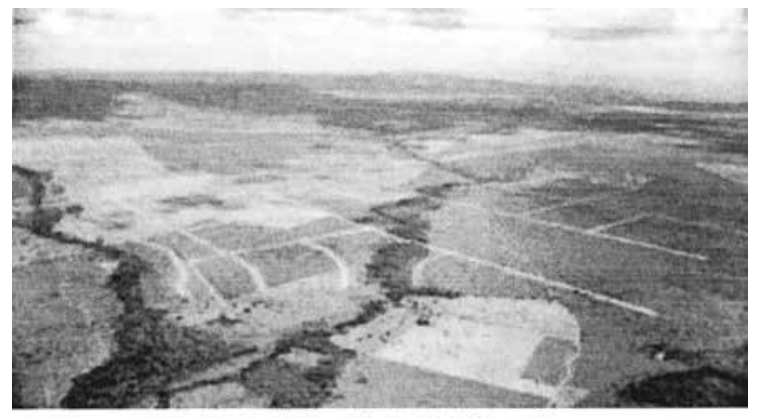

Abertura da Avenida Teotónio Sequrado
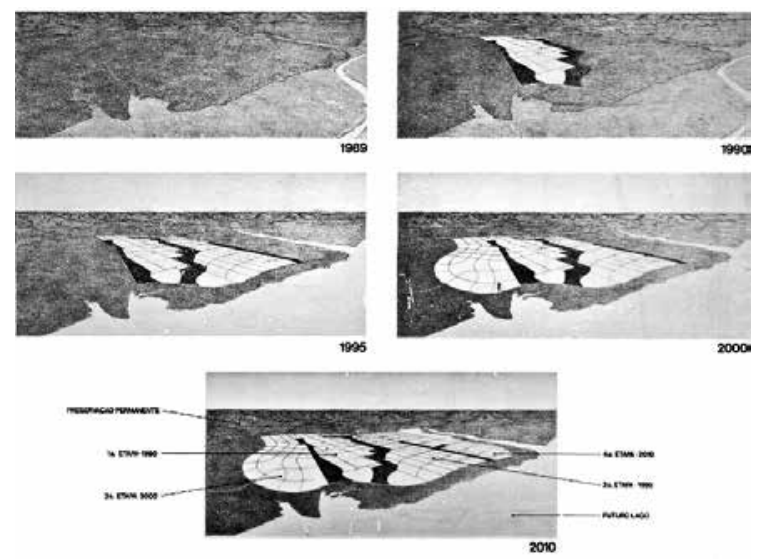

Figura 6:

Processo de implantação e urbanização da Cidade Fonte: IPUP, 2002
Figura 7:

Etapas de crescimento da cidade até o ano de 2010 e a construção do lago, realizada em 2002 Fonte: SEMUC, 2006 
desenho, bairros afastados do centro e uma grande quantidade de vazios gerados por seu espalhamento. Isso tornou Palmas uma cidade com altos custos de manutenção, tendo de construir uma grande infra-estrutura viária, de saneamento e de transporte para uma população pequena e não-concentrada. Quando fossem abertas todas as quadras na área do plano, calculava-se que poderiam viver ali com todo conforto e estrutura, cerca de um milhão e duzentos habitantes. Hoje, Palmas abriga 178.386 (IBGE, 2008). Na parte sul e norte já estavam previstas áreas de expansão, que poderiam, depois de consolidada a área do plano, tornar-se novas opções de ocupação para abrigar novos moradores.

Na Figura 8 percebe-se a morfologia atual da cidade, que extrapolou os limites do projeto antes do previsto. Nessa figura estão delimitadas as quatro áreas que definem a estrutura urbana de Palmas, e comportam-se de formas diferenciadas. A primeira é a Vila União (ao norte), região desenvolvida a partir da invasão em 1992. A segunda é a região central, onde se concentram as instâncias do poder público e do comércio e as principais quadras. A terceira é a região que se desenvolveu a partir da abertura das quadras Arse 51 e 72, a qual promoveu a ocupação no setor sudeste. A quarta são os bairros que cresceram ao extremo sul anexados à cidade: Taquaralto, Aurenys e Taquaris, todos promovidos pela ação conjunta dos gestores e comunidade.

projeto apresenta uma configuração espacial baseada em princípios funcionais, sendo o traçado viário e as unidades de vizinhança ${ }^{2}$ os principais elementos estruturadores da urbanização. Isso possibilitou que o poder público promovesse a ocupação das unidades de vizinhança, de maneira desconectada com áreas já estabelecidas, prejudicando o adensamento e a continuidade do tecido urbano. Essa ação prejudicou, de maneira definitiva, a intenção do plano antes mesmo de sua implantação.

A ruptura entre plano e gestão determinou a "esculhambação" ${ }^{3}$ das diretrizes de ordenamento previstas como essenciais para condicionar seu crescimento, revelando as arbitrariedades ocorridas na história da construção da cidade e moldando uma

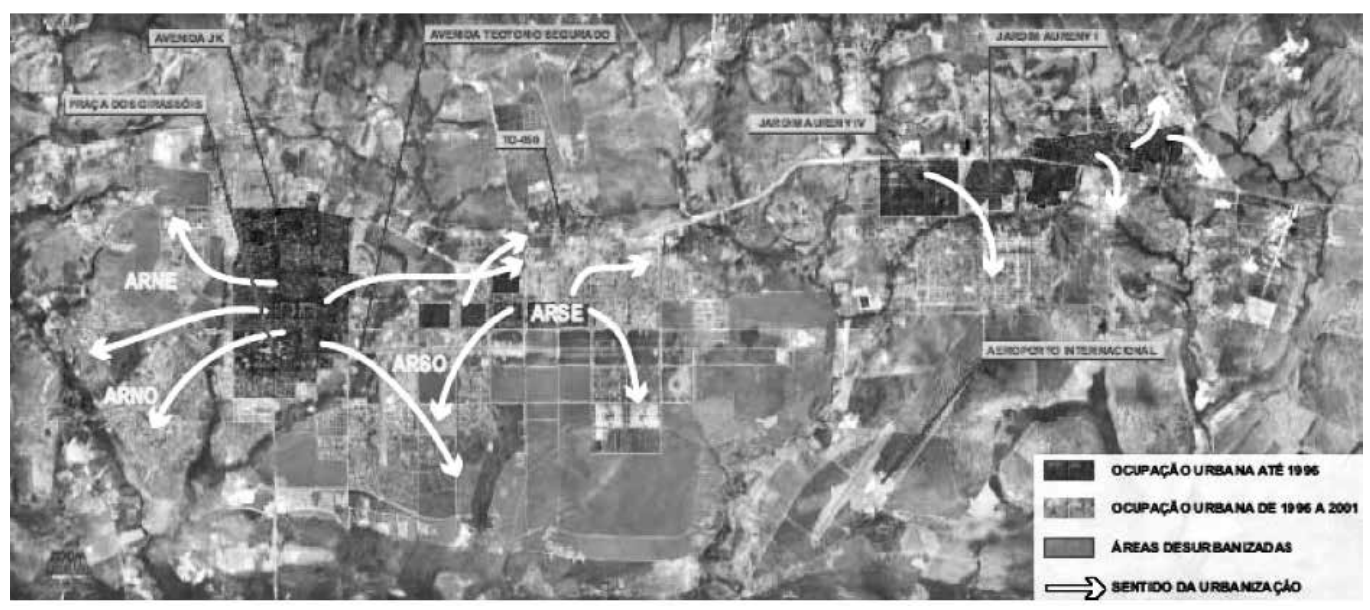

Figura 8: Ocupação da cidade até 2002. No canto direito, acima, os bairros Taquaralto e Aurenys, distritos criados para abrigar a mão-de-obra da cidade

Fonte: IPUP, 2002 
nova realidade espacial.

\section{SISTEMAS DE ESPAÇOS LIVRES EM PALMAS}

Cada unidade de vizinhança de Palmas é dotada de particularidades, seja pelo desenho, seja pelo modelo de ocupação ou apropriação ocorrida tanto no espaço público como no privado. A divisão respeita os eixos viários ortogonais que derivam da avenida Teotônio Segurado (norte-sul) e da avenida JK (leste-oeste). Embora as condições espaciais propostas pelo plano sejam as mesmas em relação às dimensões das unidades e diretrizes de parcelamento, sua diversidade morfológica resulta das diferentes configurações de espaços livres. Para essa investigação foram enumerados três setores a apresentarem as maiores densidades dentro da área planejada, sendo elas as regiões ARSE, ARNE e ARNO4.

A primeira região analisada, a ARSE, refere-se à área que apresenta a melhor infra-estrutura urbana da cidade: pavimentação, praças, transporte público e serviços, e que hoje representa, com o centro comercial no entorno da praça dos Girassóis, a principal centralidade de Palmas (Figura 9).

A Figura 11 representa a quadra com maior valorização imobiliária da cidade (ARSE
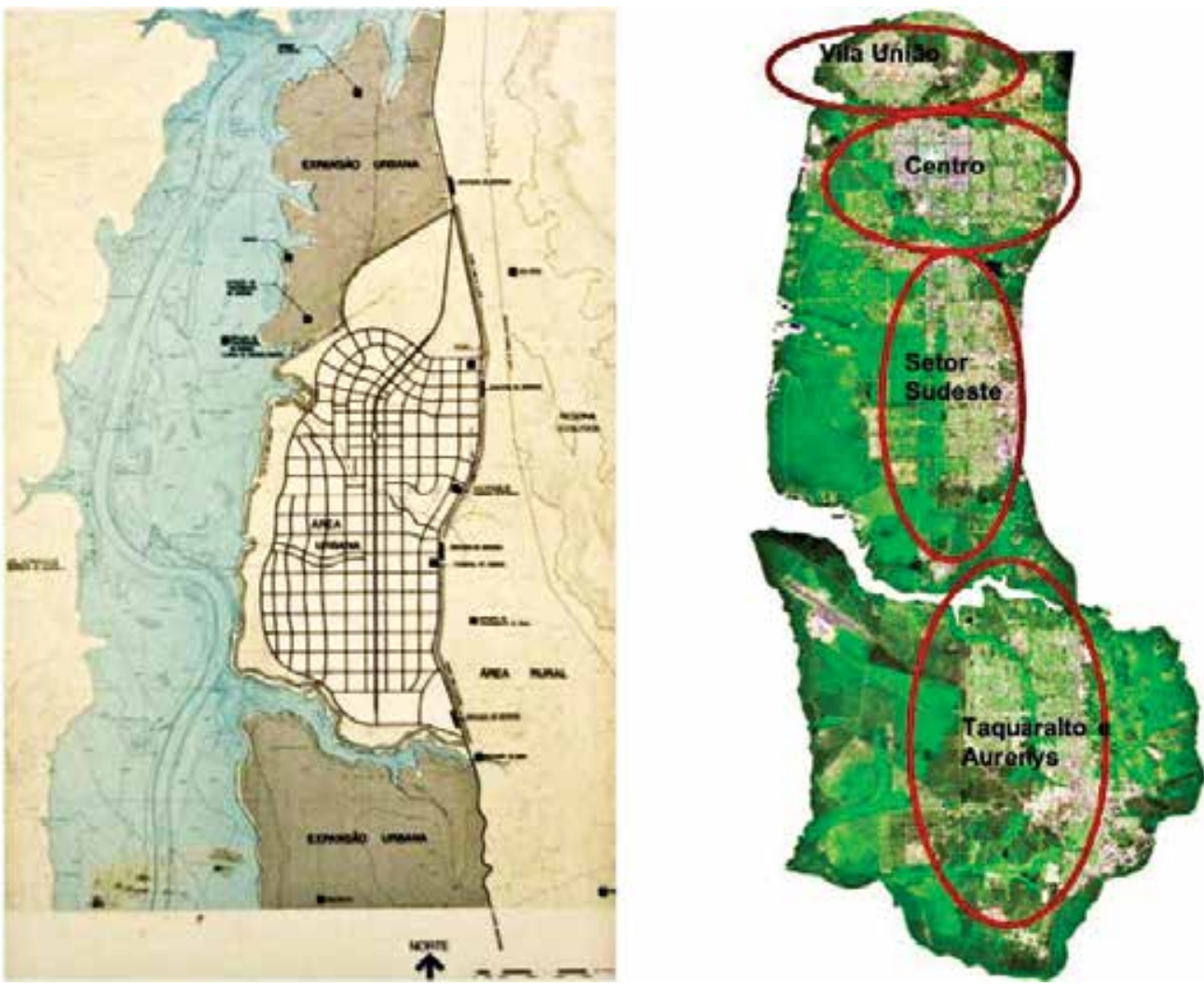

Figura 9: Morfologia do Plano de Palmas e morfologia atual da cidade. Na primeira imagem o traçado define o desenho urbano. Na segunda o traçado é abstraído por uma nova forma que se originou com o desenvolvimento da cidade

Fonte: SEDUH, 2006 
21), possuindo um desenho diferenciado das demais quadras centrais. $O$ comércio vicinal proposto pelo plano deveria se encontrar nos limites de cada uma; porém, nessa quadra, ele se localiza em seu interior, mudando consideravelmente sua condição espacial. Além disso, os lotes multifamiliares ${ }^{5}$, que pelo plano deveriam estar nas bordas, aparecem dispersos em meio ao parcelamento.

Em todas as quadras os espaços livres se caracterizam pelas áreas públicas municipais (APM), que incluem as praças, fundos de lotes e áreas de reserva do sistema viário; pela rede de ruas locais, incluindo os cul-de-sac e estacionamentos; e pelas calçadas dos lotes residenciais e comerciais. No caso da ARSE 21, as praças e áreas no fundo dos lotes ${ }^{6}$ apresentam uma unidade espacial com projetos paisagísticos implantados, nas quais se pode caminhar nas calçadas dos jardins bem cuidados, fato raro na cidade (Figura 10).

Em contraposição à região central, as quadras da área residencial noroeste (ARNO) apresentam um histórico de ocupação irregular, de invasão e de pouco investimento do setor público, moldando sua paisagem e seu contexto urbano. Novos investimentos privados possibilitam alterar essa situação, com a futura implantação do Shopping Capim Dourado e do recém-inaugurado condomínio fechado Privillege, que incorporou toda uma quadra residencial para seu parcelamento (Figura 11).

Com uma localização estratégica na entrada da cidade, próxima ao futuro shopping e ao centro comercial, a quadra ARNO 12 (Figura 12) é caracterizada pela grande quantidade de espaços livres; porém, ao contrário da ARSE 21, estes se encontram sem intervenção projetual e apropriados de diferentes modos pela população local. A dificuldade de acesso, a topografia acentuada e a ocupação desordenada propiciaram
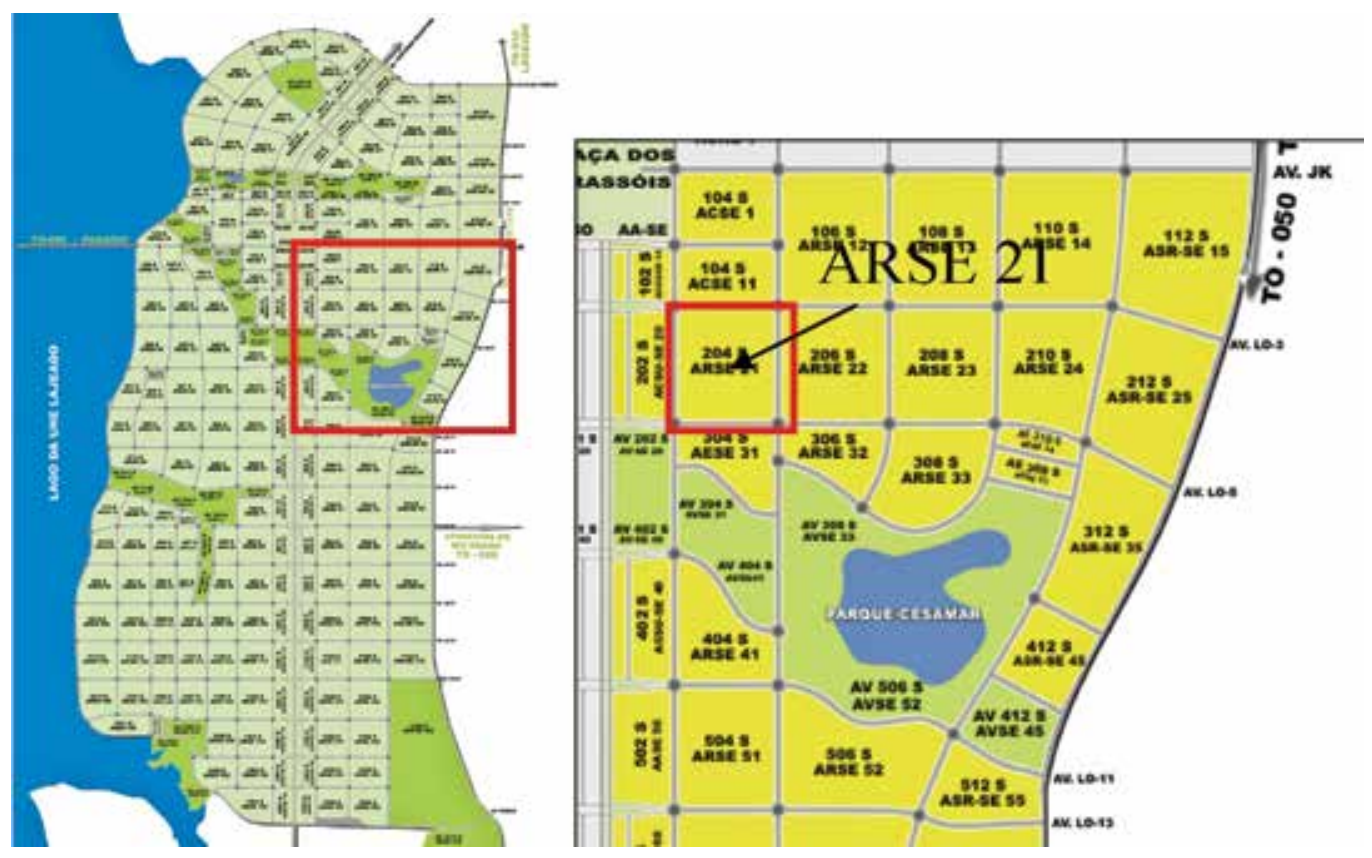

Figura 10: Região sudeste (ARSE) do plano diretor

Fonte: http://www.palmas.to.gov.br. 2008 
uma condição de difícil entendimento de seu espaço, mesmo com um parcelamento de fácil legibilidade e desenho simplificado. Ainda que apresente uma predominância de áreas livres, não existe uma relação espacial entre essas, prejudicando a continuidade e a permeabilidade de sua malha urbana.

A região nordeste (ARNE) é um híbrido das duas áreas citadas anteriormente, absorvendo influências de ambas, principalmente pela proximidade das áreas mais expressivas de Palmas (Figura 13). As quadras na avenida JK se assemelham às da re-

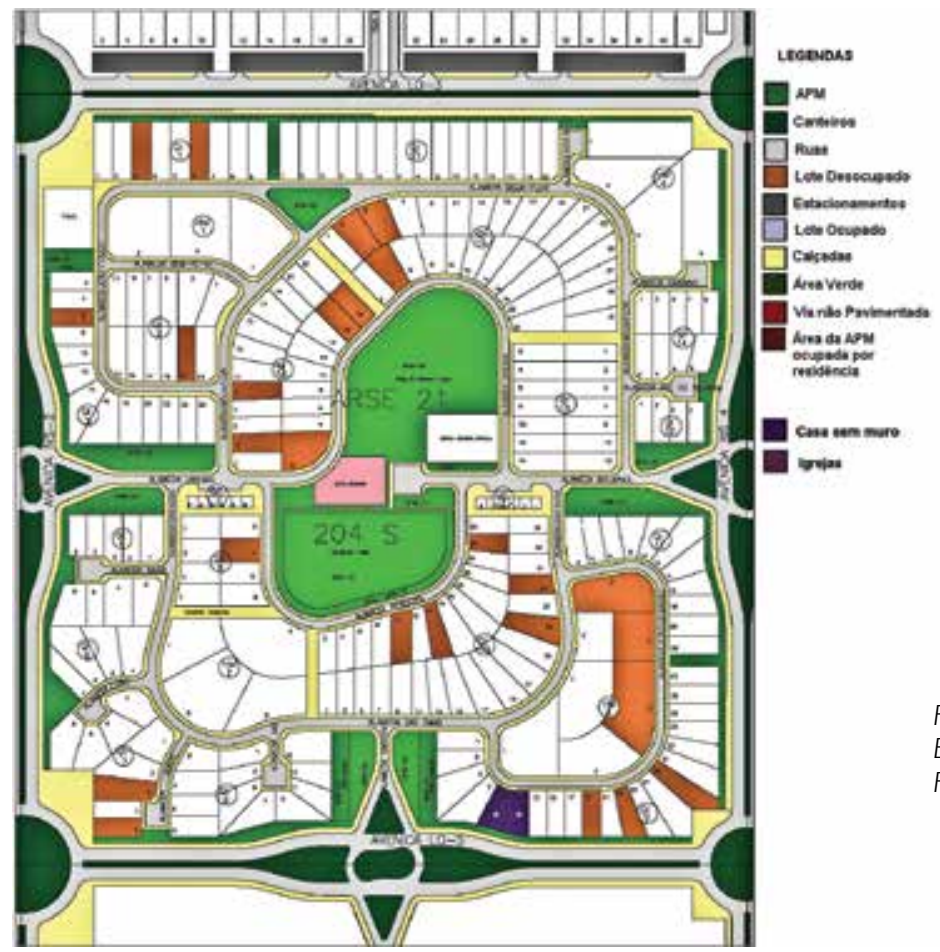

Figura 11:

Espaços livres da quadra ARSE 21

Fonte: SEL - Palmas, 2008

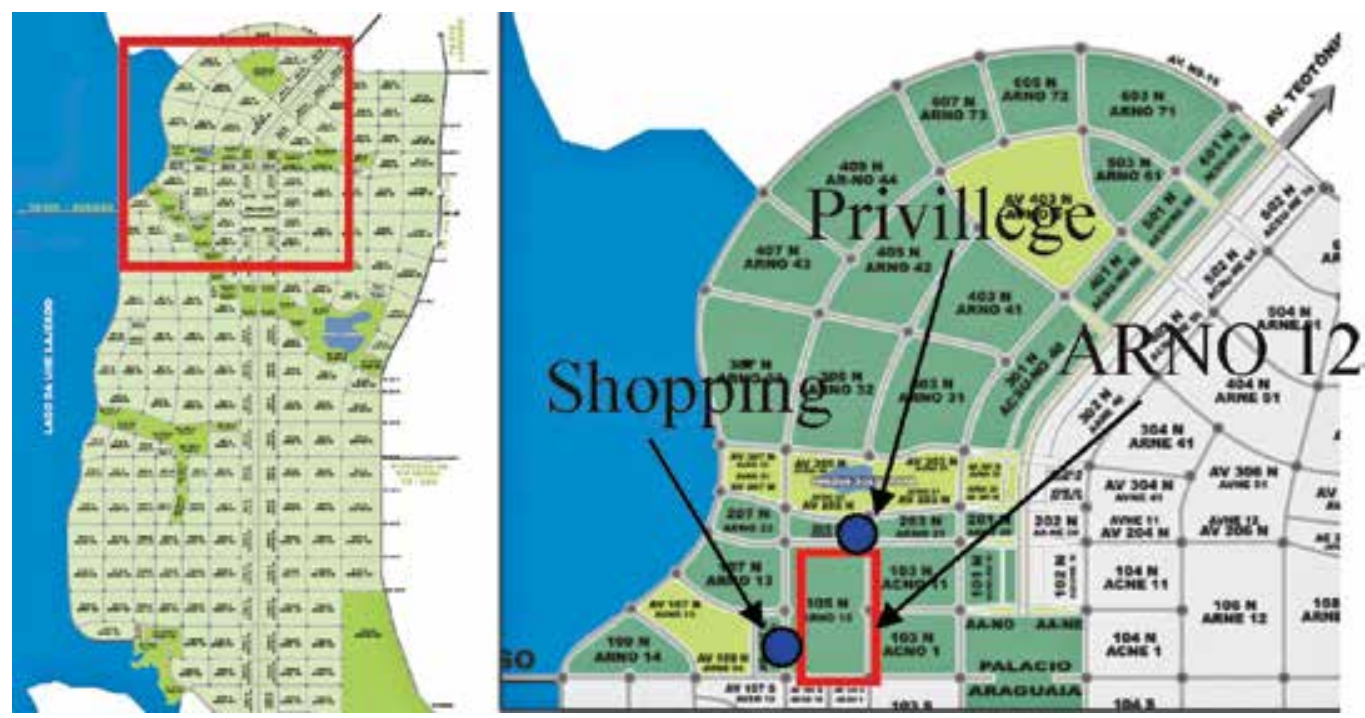

Figura 12: Região noroeste (ARNO) do plano diretor

Fonte: http://www.palmas.to.gov.br. 2008 
gião sudeste, enquanto as situadas além do córrego Sussuapara e próximas à Teotônio Segurado sofrem influência da região noroeste.

A fragmentação territorial caracteriza a imagem e o contexto urbano da região, com pouca infra-estrutura viária, de lazer e de serviços, dependendo das áreas adjacentes. Isso se deve ao fato de a cidade não seguir o conceito inicial para sua ocupação, ao desinteresse do poder público, privilegiando algumas áreas em detrimento a esta, e pelo vetor de crescimento de a cidade se localizar na parte sul do plano.

A quadra ARNE 24 se localiza na transição entre as duas áreas de influência da região (sul e norte), e, devido a isso, possui características de ambas. A parte sul da quadra é hoje o principal vetor de crescimento imobiliário, devido à facilidade de acesso, à presença da praça e à proximidade com a avenida JK. A parte norte, em contrapartida, isola-se devido à inexistência de acessos diretos e encontra-se limitada pela futura área comercial, contida em ruas de difícil permeabilidade e sem integração com o restante da malha. A praça é uma das variáveis responsável por essa fragmentação entre norte e sul da quadra, na qual sua escala avantajada e seu desenho com problemas de legibilidade (ora com ruas de contorno, ora com edificações nas divisas

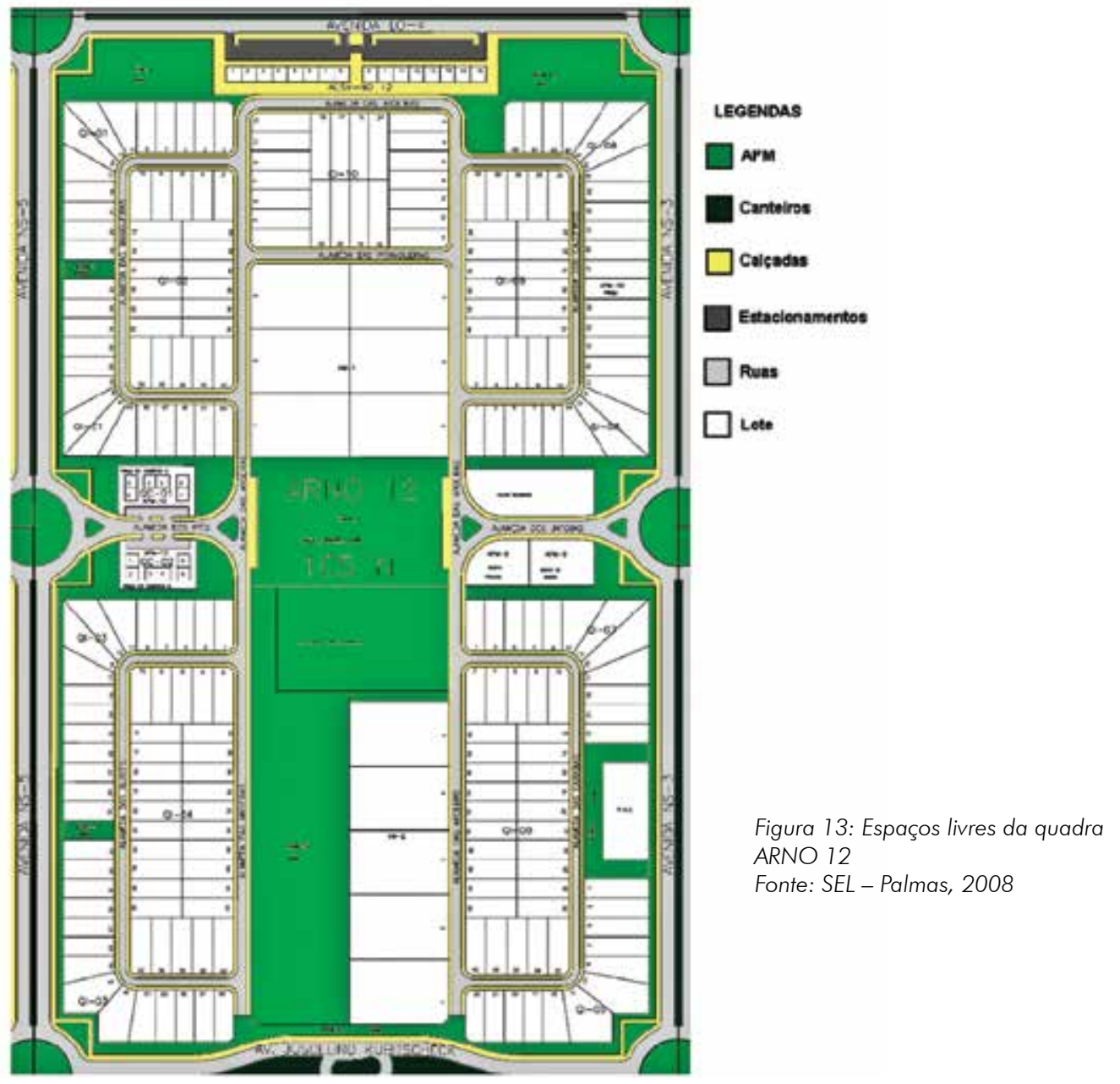


e/ou caminhos para pedestres) não agregam os elementos urbanos idealizados a fim de prover qualidade ao espaço livre, tornando-o disperso (Figura 14).

Pelo conceito original, o sistema de espaços livres deveria ser o elemento integrador do traçado da cidade; porém, atualmente, este se manifesta como um conjunto de fragmentos que não se conectam, ocasionando a descontinuidade do espaço urbano. Aqueles se constituem em diferentes aspectos e modalidades para qualificar a malha urbana de maneira pontual, introduzindo, na paisagem, um imaginário: que a quan-

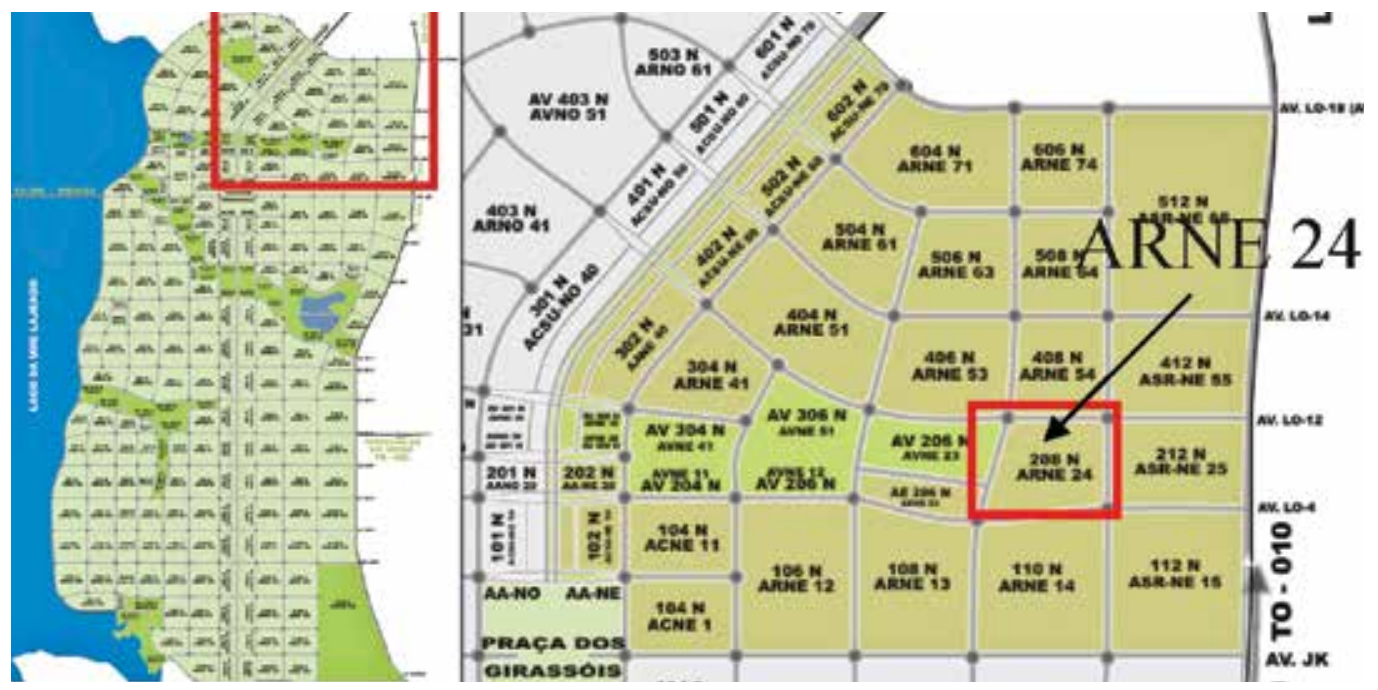

Figura 14: Região nordeste (ARNE) do plano diretor Fonte: http://www.palmas.to.gov.br

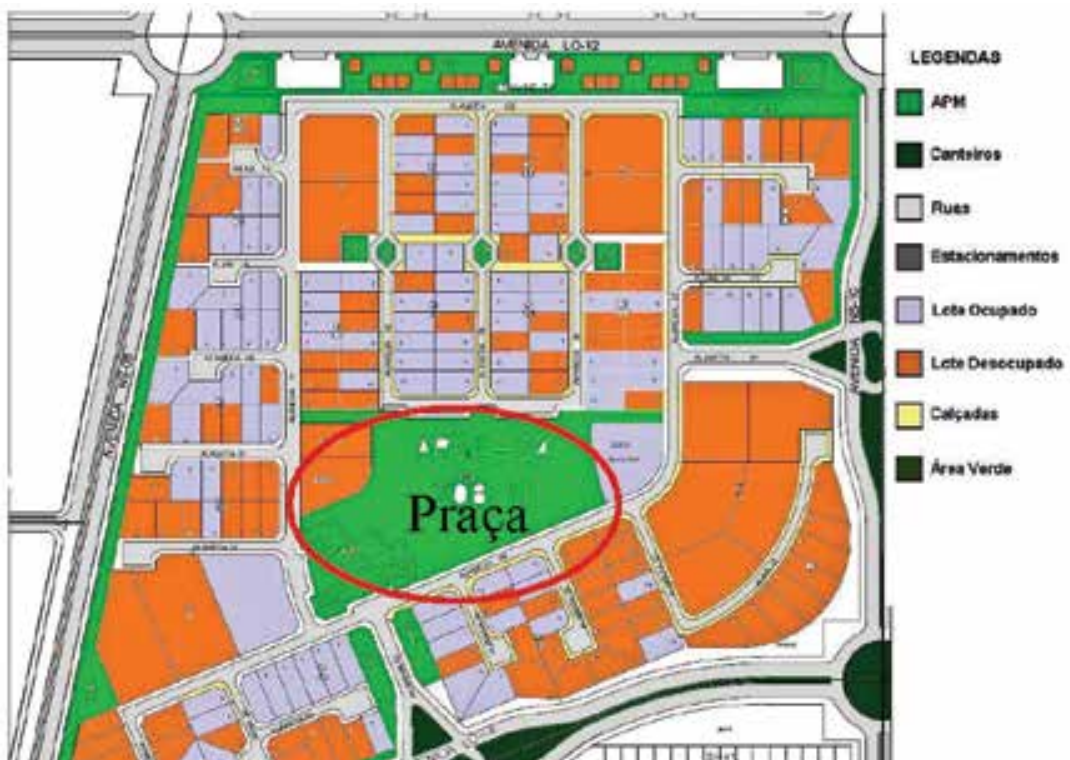

Figura 15:

Espaços livres da quadra ARNE 24

Fonte: SEL - Palmas, 2008 
tidade desses espaços pudesse proporcionar uma qualificação em um novo contexto de cidade contemporânea.

\section{LIMITES, CONFLITOS E POTENCIALIDADES}

A integração e o alto nível de mobilidade e acessibilidade ao espaço urbano permitem às cidades intensificarem seu papel de promotoras das relações sociais em diferentes níveis. A derrubada das muralhas das antigas cidades, proteção e limites de seu traçado urbano promoveram não só uma nova conformação espacial, mas permitiram sua expansão e conexão, tanto de sua estrutura física como de sua estrutura social, configurando novas sociedades. Atualmente, os limites se caracterizam por outras barreiras, tanto físicas como sociais, definindo fragmentos que restringem o uso dos espaços como elementos de promoção da interação social.

O traçado ortogonal é historicamente adequado quando se trata de integração da malha urbana, permitindo uma continuidade espacial, essencial para a qualidade das cidades. Mesmo os planejadores de Palmas tendo adotado esse modelo no macroparcelamento, a fragmentação, que ocorre na escala do micro (unidades de vizinhança), inviabiliza a criação de um sistema de espaços livres contínuos.

A liberdade projetual que cada quadra pode apresentar interferiu na continuidade espacial que o plano, como um todo, almejava. $\bigcirc$ projeto, que foi generoso com a categoria de espaços livres, esbarra em um dos principais conflitos encontrados na cidade: a descontinuidade destes.

Espaços que não se conectam, barreiras proporcionadas pela enorme quantidade de muros pela cidade, a dificuldade de acessos e locomoção de pedestres, tanto no interior como nas bordas das quadras, e as grandes avenidas de difícil transposição exemplificam alguns dos conflitos gerados por essa descontinuidade espacial. Estabelecer um desenho urbano que permite novamente a integração dessas áreas é um dos principais desafios aos pensadores da questão urbana.

Mesmo com os inúmeros conflitos apresentados, os espaços livres de Palmas apresentam potencialidades as quais, se estudadas, analisadas e compreendidas no âmbito de uma esfera conjunta entre o público e o privado, permitem trazer uma nova condição sociourbana para seus moradores.

\section{Notas}


(1) Escritório responsável pelo desenvolvimento do projeto urbanístico de Palmas-TO.

(2) São consideradas "bairros" resultantes do traçado viário fechado, delimitados por grandes avenidas estruturadoras, com dimensionamento básico de 700 × 700 metros e vias locais de acesso aos lotes no interior dessas unidades.

(3) Termo utilizado por Oscar Niemeyer em um depoimento informal aos autores do projeto sobre a falta de um plano de massas para o projeto urbanístico de Palmas-TO, conforme relato do Grupo Quatro.

(4) As siglas se referem ao uso e à posição geográfica no plano. Ex: Área Residencial Sudeste (ARSE).

(5) Em Palmas há uma diferenciação nas áreas residenciais para lotes unifamiliares, com metragem quadrada entre 360 a 600, destinada para uma ou, no máximo, três habitações, e multifamiliares, com metragem quadrada de 700 a 5.000 , para condomínios verticais ou horizontais.

(6) O parcelamento de muitas quadras faz com que os lotes residenciais se voltem para as ruas internas, ficando o fundo para as avenidas arteriais, separadas por áreas verdes.

\section{Bibliografia}

GRUPOQUATRO. Plano básico/memória - 1989. Documento técnico-eletrônico. 1989.

AUGÉ, Marc. No-Lugares y Espacio Publico. Quaderns 231 - Water/Land, Barcelona, p. 6-15, 1997.

CALDEIRA, Tereza Pires. Cidade de muros: Crime, segregação e cidadania em São Paulo. São Paulo: Ed. 34/Edusp, 2000.

CARLOS, Ana Fanny Alessandri. A (re) produção do espaço urbano. São Paulo: Edusp, 1994.

INSTITUTO BRASILEIRO DE GEOGRAFIA E ESTATÍSTICA (IBGE), Censo 2007. Cidades@. Disponível em:http://www. ibge.gov.br. Acesso em: ago. 2008.

MAGNOLI, Miranda Martinelli. Espaço livre: objeto de trabalho. Paisagem e Ambiente: Ensaios, São Paulo, n. 21, p. 175-197, 2006.

SANTOS, Milton. Metamorfoses do espaço habitado. São Paulo: Hucitec, 1991.

\section{Sites}

Prefeitura de Palmas: <htpp://www.palmas.to.gov.br

WWF: htpp://www.wwf.org.br 
